\title{
How changing API terms changed Instagram's domain? A bibliometric analysis
}

\author{
RICHARD, HARTMAN*
}

Department of Management, Faculty of Economics and Management Czech University of Life Sciences Prague

Email: hartman@af.czu.cz

TEREZA, ŠíMOVÁ

Department of Management, Faculty of Economics and Management Czech University of Life Sciences Prague

Email: simovat@lib.czu.cz

In 2018 Facebook blocked a public Application Programming Interfaces (API) that could be used to download data from Facebook and Instagram. Much uncertainty still exists about the effect on social media research due to changes in Instagram API conditions. The presented paper provides an overview of the Instagram domain in terms of a research area. The main focus of this research is on the comparison of the key topics before and after the change of the Instagram API terms (comparing Instagram's research domain before and after 2018). A partial goal was to find out how the change in the conditions of the Instagram API has changed the number of social media research itself. We used a bibliometric approach to map the domain of Instagram. The paper has identified key topics in the domain of Instagram. Between the years 2010 and 2018 the key topics were gender, behavior on social media, dissemination of information, and platform selection. After the change of Instagram API conditions, after 2018, the key topics were gratifications, body image, dissatisfaction, and basic Instagram topics. The paper has found that generally, there was no change in research topics, nor the number of papers published after the Instagram API condition. Further study should focus on establish the relationships between Instagram use and psychological well-being; investigate the motives for Instagram use a study the effect of Instagram API on research with the use of different methods; gaining a better understanding of social media consumer activity; establish whatever our key topics are relevant to other social media platforms (Facebook, Twitter or Tiktok); study Instagram domain on different citation databases (e.g., in Scopus). This paper has also raised important questions about whether the Instagram API should be or should not be open for research purposes.

CCS CONCEPTS • Applied computing • Law, social and behavioral sciences $•$ Sociology

Additional Keywords: Application Programming Interfaces, Bibliometrix, Social Media Research, Social Media ACM Reference Format:

Richard, Hartman, Tereza, Šímová, 2021. Topic analysis on the Instagram social network based on Web of Science Database. In ICCTA 2021: 7th International Conference on Computer Technology Applications, July 13-15, 2021, Vienna, Austria. ACM, New York, NY, USA, XX pages. https://doi.org/ (the DOI information will be completed after uploading copyright).

\footnotetext{
* Corresponding author.
} 


\section{INTRODUCTION}

Online social networks have become a part of the daily life of many peoples. An example is an average adolescent (individuals between ages 10 and 24 - WHO's the definition [1]), who spends 3.2 hours on social networks every day [2]. About 3.6 billion users currently use social networks and according to the forecast, social networks in 2025 benefit more than 4.41 billion users [3]. When comparing the prediction of the number of social network users and the global population for 2025 (8 184437460 peoples) [4] social networks will be used by about $54 \%$ of the planet's population. The so-called active and inactive digital footprints are left behind by social network users. Due to a large number of users and the corresponding amount of this data, it is possible to use this data for both research and marketing activities. Examples are studies that have focused on the prediction of the Big 5 personality traits [5], identification of customer experience on the Farmers market [6] or with Organic Food [7], Identification differences between Developing and Developed Countries in the field of Corporate Social Responsibility [8], sustainability [63], gamification [64] or healthy food area [9, 65]. Social media research has grown in importance in light of the recent pandemic Covid-19 [61] when online communication became one of the key elements of keeping in touch with your loved ones. [1]), who spends 3.2 hours on social networks every day [2]. About 3.6 billion users currently use social networks and according to the forecast, social networks in 2025 benefit more than 4.41 billion users [3]. When comparing the prediction of the number of social network users and the global population for 2025 (8 184437460 peoples) [4] social networks will be used by about $54 \%$ of the planet's population. The so-called active and inactive digital footprints are left behind by social network users. Due to a large number of users and the corresponding amount of this data, it is possible to use this data for both research and marketing activities. Examples are studies that have focused on the prediction of the Big 5 personality traits [5], identification of customer experience on the Farmers market [6] or with Organic Food [7], Identification differences between Developing and Developed Countries in the field of Corporate Social Responsibility [8] or healthy food area [9]. Social media research has grown in importance in light of the recent pandemic Covid-19 [61] when online communication became one of the key elements of keeping in touch with your loved ones.

Instagram is a social network focused on sharing mobile photos, and it gained its popularity mainly due to the effortless and fast ability to share pictures to which users can apply filters, which are available for free in the application. The social network Instagram was founded on October 6. 2010 and in the first year of its launch, it already had 1 million users. It exceeded the limit of 100 million users in 2013 when the popularity of this application began to grow very quickly. At the beginning of 2017, it was estimated that Instagram would exceed 800 million users at beginning of 2019, making it the fastest growing social network to date [10]. This expectation was exceeded at the end of 2018 when it exceeded the limit of one billion active users [11]. Facebook, which bought Instagram in 2012 for $\$ 1$ billion, also has a share in the success of this growth. In 2018, it was estimated that the value of Instagram had grower to $\$ 100$ billion $[12,13]$. Instagram has become one of the most significant worldwide social networks, which affects the lives of many inhabitants. For example, in Spain, it is the fastest growing social network focusing on lifestyle, beauty, and fashion [14]. This is also supported by [15], which states that Instagram is the most widely used platform for sharing opinions in the Fashion industry, which impacts consumer shopping behavior. Thus, it is a platform that has great potential to influence shopping behavior and the entire lifestyle of individuals and groups, and that's also the downside of Instagram. As Highfield and Leaver [59] stated the privacy on social media is a critical issue for social media research. The problem is that the consequence of sharing is not immediately understandable to users [59]. As a result of the 
"Cambridge analytics affair" [16, 60], when the company that worked with Donald Trump's election team harvested over 50 million Facebook profiles, a public Application Programming Interfaces (API) that could be used to download data was blocked by Facebook. This decision affects Instagram as part of Facebook as well. As Perriam, Birkbak, and Freeman [60] mentioned it seems "that Facebook does not intend to support research, not even not-for-profit academic research supposed to serve the public good".

Much uncertainty still exists about the effect on social media research due to changes in Instagram API conditions. The article aims to provide an overview of the Instagram domain in terms of the research area (through articles published in the Web of Science database). The main focus thereafter was on changing key topics after changing the terms of the Instagram API (comparing Instagram's research domain before and after 2018). A partial goal was to find out how the change in the conditions of the Instagram API has changed the number of social media research itself.

\section{METHODOLOGY}

We used bibliometric analysis to map the domain of Instagram. This method is particularly useful to study the entire domain to show the main themes and the connections between them, and to emphasize new trends as well as the existence of research gaps [17]. Another advantage of using bibliometric analysis is that it allows systematic, transparent, and reproducible research [18]. In the first step, we obtain bibliographic references from the Web of Science (WOS) on May 7, 2021. To obtain references from WOS we used a search query: (TS = "instagram") AND Language: (English). Timespan we set for all years (1945-present) and we searched through indexes: SCI-EXPANDED, SSCI, A\&HCI, CPCI-S, CPCI-SSH, ESCI, CCR-EXPANDED, IC. Search captured 3128 references, which we included in the bibliometric analysis. Bibliometric analysis has been conducted in RStudio using a Bibliometrix package designed by Aria and Cuccurullo [17]. To capture the influence of change in the terms of using API, we created two data sets. The first data set contained articles published from 2010 to 2018, the second data set contained articles published from 2019 to 2021. To create conceptual structure maps, we used Keywords Plus from WOS. A conceptual structure map of Keywords Plus has been created with the use of K-means clustering and multiple correspondence analysis. The created conceptual structure maps represent key factors, which have been discussed by researchers in the domain of Instagram. Factor coordinates show the correlations between factors - the closeness of the factors suggests that the scientists addressed them together. At the same time, the factors that are close to 0-0 coordinates are the ones that have been addressed most often [19]. Authors contributing to the transparency, reproducibility, and robustness of this paper and all supporting materials (script, data) can be found at Open Science Framework (link).

\section{RESULTS:}

The first research paper on Instagram, which is indexed in the Web of Science, was published in 2010. From that moment topics dealing with Instagram become more and more popular (as is shown by the increasing trend of the number of articles indexed in Web of Science). The increasing trend of the number of publications in the Instagram domain was confirmed also in Scopus [20]. 


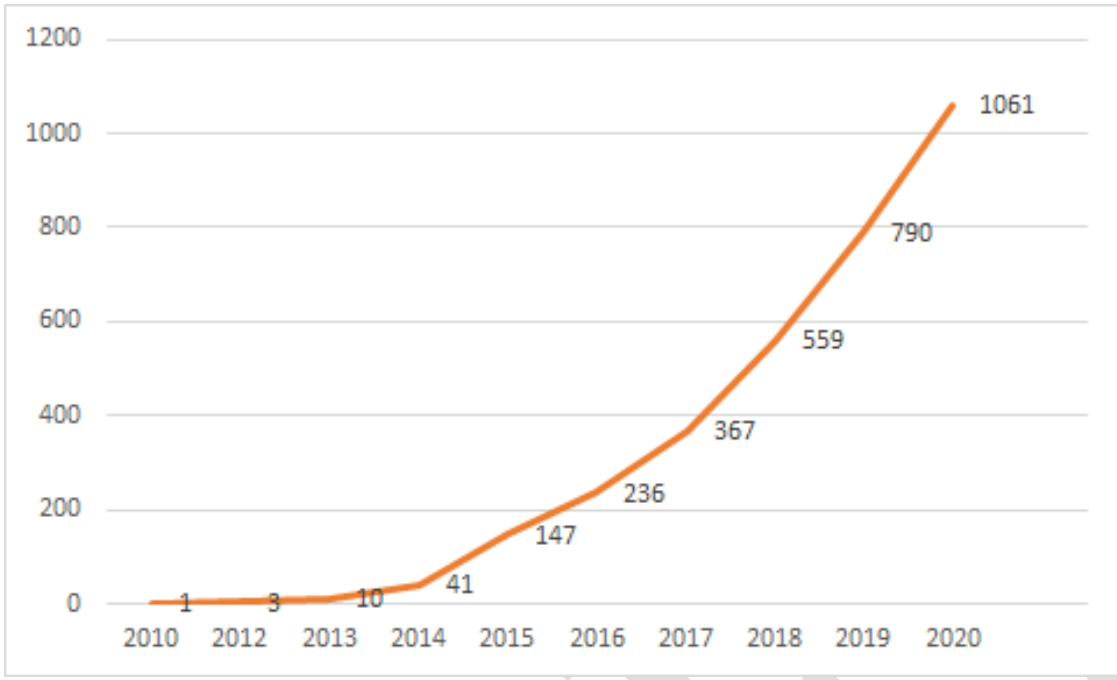

Figure 1 Trend of publication in the Instagram domain

As can be seen in Figure 1, the number of articles did not change due to the change of terms of API after 2018, the trend was sill increasing. Those results are contradictory to those by Perriam, Birkbak, and Freeman [60] who claim there are fewer studies due to API restrictions. Our result has thrown up many questions for further investigation. For example, how researchers access data if not with public API? What tools are available for researchers who would like to explore data from Instagram? Or about whether the Instagram API should be or should not be open for research purposes. If the debate about Instagram API is to be moved forward, future research on this topic is needed.

\section{Topics before the change of conditions of Instagram API use}

Figure 2 shows topics that were discussed in research between 2010 and 2018 (before the change of Instagram API terms). Topics are divided into four clusters by the K-means clustering and multiple correspondence analysis.

Red cluster (letter A) illustrated topics related to the platforms themselves. Researchers have focused on the different type of platforms and their effect on the users. For example, Boczkowski and Matassi [21] study how the constellations of meaning assigned to each platform influence users' behaviors. Erz and Marder [22] discovered platform drivers that affect the frequency at which users click and add hashtags, as well as the number of hashtags a user may use in a message. Erz and Marder [22] also discovered that potential influencers were heavy hashtag users, largely motivated by self-presentation motivations, and scored higher on narcissism, extraversion, and self-monitoring than followers.

Green cluster (letter B) illustrated topics related to the dissemination of information. The findings by Fraustino and Lee [23] show that 360-degree video depicting the aftermath of a natural disaster improves attitudes toward the content's beneficial effects. Rathore and Ahmad [24] suggest a framework for exploring geosocial networks 
and collecting data to make real-time decisions and detect different events. Cenni and Nesi [25] demonstrated an analytics platform capable of data ingestion and processing, as well as the computation of analysis metrics, which allowed for further statistical observations and investigations.

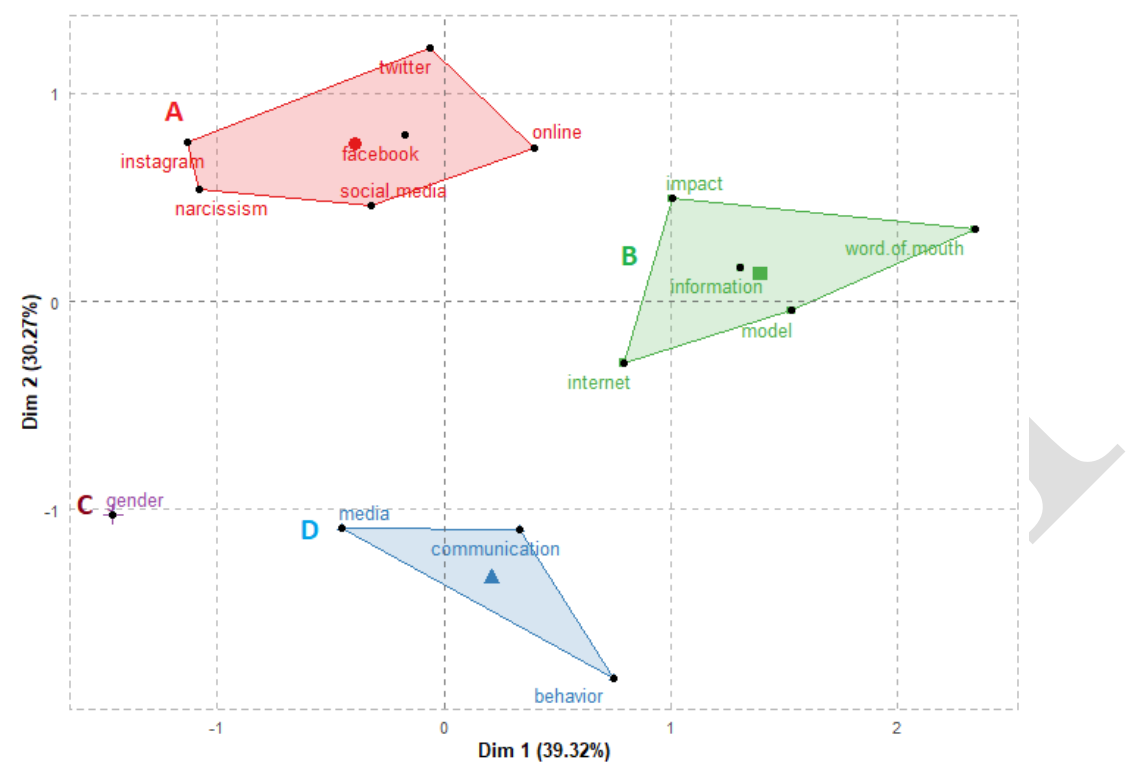

Figure 2 Conceptual Structure Map of topics from 2010 to 2018

A small amount of research focused also on gender issues - the purple cluster (letter C). Thelwall and Vis [29] for example study the differences between men and women and their habits with sharing photos on social networks. Research by Döring, Reif and Poeschl [30] focused on gender stereotyping in selfie. Researchers also focused on gender in connection to marketing activities. Ye et al. [31] investigate the use of hashtags from a gender perspective and they suggested to organizations to consider gender during targeting on Instagram. A similar suggestion had research by Jeon, Jwon, and Han [32] who study gender and biological sex for marketing purposes. As can be seen from the location and size of the purple cluster, the gender issue on Instagram had the potential for future research - which is confirmed by the position of the gender topic in Figure 3 - red $(A)$ and blue (D) cluster. [29] for example study the differences between men and women and their habits with sharing photos on social networks.

Blue cluster (letter D) illustrated behavior on social media. Communication is the basis of social media. Much research has been focused on social media behaviors, between 2018. Sherman et al. [26] study the effects on the brain and behavior in teenagers. Sherman et al. [26] also compare the effects of "likes" and face-to-face positive feedback. Instagram is also used for its business potential. Intensive posting on Instagram can lead to increased customer engagement [27], and consumer hedonism and satisfaction [28]. The green (B), red (A), and blue (D) clusters become a part of the large red cluster in the second investigated period (after 2018). 


\section{Topics after the change of conditions of Instagram API use}

Four clusters were generated from the second data set by the multiple correlation analysis (Figure 3). As Figure 1 shows the number of articles in 2019, 2020 has increased, for that reason the number of topics in clusters has increased in comparison to the first conceptual structure (Figure 2). Those results are contradictory to those by Perriam, Birkbak and Freeman [60] who claims the API restrictions have a damaging impact on social media research.

Clusters identified before the API change of use (before 2018) merged into one large red cluster (letter A). We called the red cluster (A) basic Instagram topics. As can be seen from Figure 3, the increase of interest in Instagram research has connect a lot of different topics into one large cluster. For instance, the topics connected to networking sites and college student - Lemay and Bazelais [37] investigate the impact of social networking site frequency, length, and problematic (i.e., maladaptive) usage on perceived success expectancy and actual academic performance in a group of college-level students. Recent study by Cavus et al., [57] also focus on the networking sites and its efficacy on education during the recent pandemic Covid-19. A broad variety of studies have examined engagement in online media in a connection to gender, age, but also in a connection to self-expression and marketing propose. Hasim, Sharin and Wahid [58] study the influence of Instagram on consumer purchase intention. Romero and Moro's shows that short food videos shared on social media have increased potential tourists' awareness of the destination's image, especially the flavor characteristics of the destination's food and the local social atmosphere [33]. On the self-expression topic the article by Feher [34] provides a detailed overview of online personal strategies as well as the evolution of theoretical ideas regarding digital identity and the online self. McCrory and Best [36] study the influence of visually rich social media such as Instagram on the mental health of adolescents. The position of topics such as health, gender, or self and image is in proximity to blue cluster (letter D).

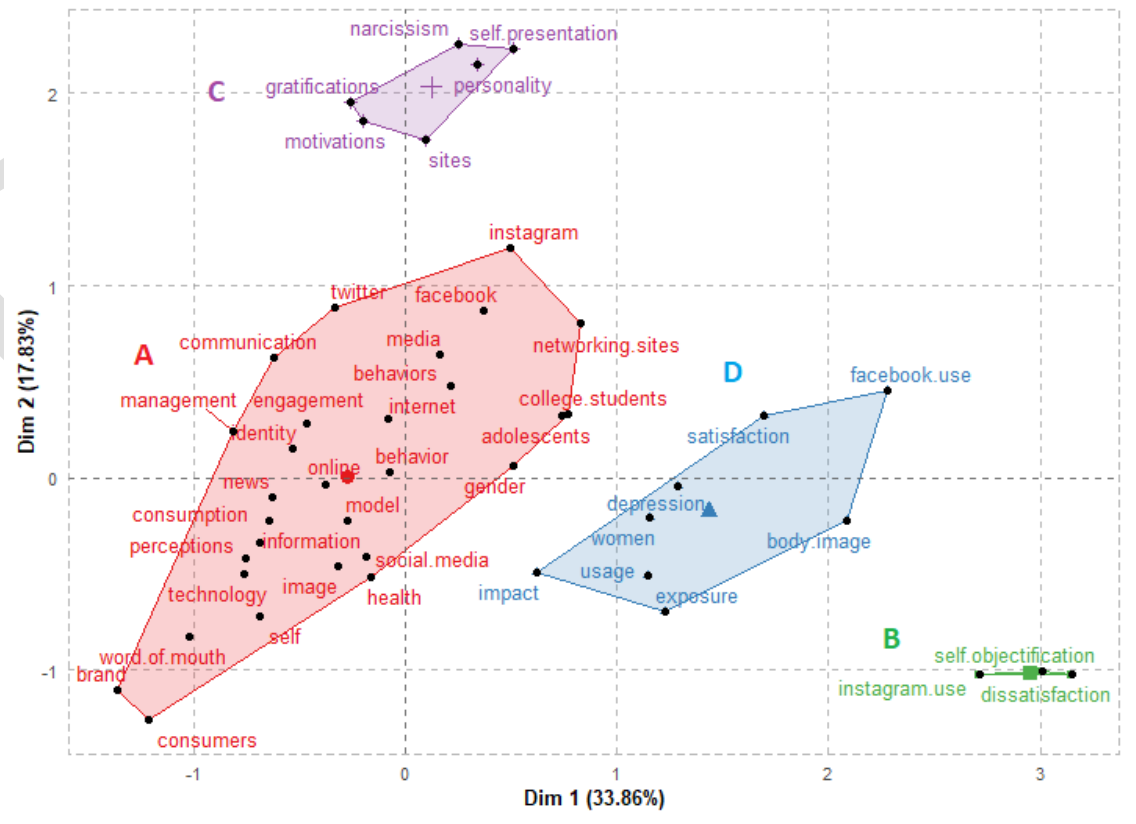

Figure 3 Conceptual Structure Map of topics from 2019 to 2021 
Blue cluster (D) illustrate the effects of using Instagram with connection to self-perception. In the blue cluster we can see topics such as body image, exposure, usage, women, depression, satisfaction or impact. As Brown and Tiggemann [41] states much research has been done on the topic of women's body dissatisfaction after exposure to images from Instagram. For example, Tiggemann, Anderberg and Brown [44] investigate the effect of positive or negative captions of women's body images. Another research by Cohen, Newton-John and Slater [45] focused on using Instagram and Facebook and its use related to issues of body image of young women. Brown and Tiggemann [46] claims, that images of attractive celebrities can affect women's body self-perception. Gender discrepancies influence Hollenbaugh's [35] mediation model, which shows that more selfie exposure is linked to higher facial dissatisfaction. Jiand and Ngien [47] states that social comparison increases social anxiety which can lead to depression [48], exactly as is shown in the blue cluster. Contradictory a recent study by Masciantonio et al [62] showed that an active usage of Instagram positively influences the well-being of users. Our conclusion is that use of Instagram and body image or exposure affect satisfaction with one's body and it can lead to depression, especially in women. These conclusions are consistent with those by Baker, Ferszt and Breines [49] who states that Instagram negatively impacts women's body image, and also with those by Jiand and Ngien [47] - Instagram is associated with the social comparison. Future research based on the cluster A and $D$ should focus on closer relationships between Instagram uses and psychological well-being, not only with women; on deeper understanding of user behavior on social media with connection to marketing, consumers, brand as well as to health and well-being (for example with the use of machine learning and natural language processing).

Purple cluster (letter C) illustrate motives, which are related to most main reasons for Instagram use. These results support those by Sheldon and Bryant [38] who identify as the main reason for Instagram use surveillance, documentation, coolness, and creativity. Basically, people create content on social networks to share information with other users. The reason, however, is self-presentation, narcissism, and gratification. This cluster focuses on studies that address these motives [39-43]. Position of the purple cluster suggests that motives for Instagram use have the potential for future research.

The green cluster (letter B) illustrates self-objectification and dissatisfaction on Instagram social network. Selfobjectification is conceptualized mainly as an individual difference or trait and has been associated with a variety of adverse body image outcomes [50]. This area is very important in the field of social networking researched because it has a connection with negative psychological consequences [51-53] through appearance dissatisfaction [54]. This is primarily an area that is related to selfies in women [55, 56]. Green cluster is thematically similar to the blue cluster, for that reason the future research should be targeted in a similar way as in blue cluster - deeper understanding of Instagram uses and psychological well-being.

\section{CONCLUSION}

The present paper, for the first time, provided an overview of the Instagram domain in terms of the research area. The main focus of this research is on the comparison of the key topics before and after the change of the Instagram API terms (comparing Instagram's research domain before and after 2018). A partial goal was to find 
out how the change in the conditions of the Instagram API has changed the number of social media research itself.

The paper showed that the number of articles did not change due to the change of terms of API after 2018, which thrown up many questions for further investigation. For example, how researchers access data if not with public API? What tools are available for researchers who would like to explore data from Instagram? Or about whether the Instagram API should be or should not be open for research purposes.

The paper has also identified key topics in the domain of Instagram. Between the years 2010 and 2018 the key topics were gender, behavior on social media, dissemination of information, and platform selection. After the change of Instagram API conditions, after 2018, the key topics were gratifications, body image (connected to gender topics), dissatisfaction, and basic Instagram topics (such as engagement in online media in a connection to gender, age, but also a connection to self-expression and marketing propose).

Further research is required to (1) establish the relationships between Instagram uses and psychological wellbeing, not only with women, (2) investigate the motives for Instagram use, (3) study the effect of Instagram API on research with the use of different methods, (4) gaining a better understanding of social media consumer activity. A further study is also needed to (5) establish whatever our key topics are relevant to other social media platforms (Facebook, Twitter, or Tiktok) and whether the Instagram domain is the same in other citation databases (e.g., in Scopus).

The weakness of this study is the bibliometric approach itself. We analyzed only Keywords Plus from only the Web of Science database.

\section{ACKNOWLEDGMENTS}

We would like to thank doc. Ladislav Pilar for comments on the manuscript. This paper was supported by the Internal Grant Agency (IGA) of FEM CULS in Prague, registration no. 2020B0004-Use of artificial intelligence to predict communication on social networks.

\section{REFERENCES}

[1] WHO, 2021.Adolescent health. Retrieved May 10, 2021. from: https://www.who.int/southeastasia/health-topics/adolescent-health

[2] Tankovska, H. 2017. Daily time social among teens and young adults. Retrieved May 10, 2021, from https://www.statista.com/statistics/800821/average-daily-time-spent-social-media-teens-young-adults/

[3] Tankovska, H. 2021. Number of social network users worldwide from 2017 to 2025. Retrieved May 10, 2021 , from https://www.statista.com/statistics/278414/number-of-worldwide-social-network-users/

[4] World Population Projections - Worldometer. 2021. Retrieved May 10, 2021, from https://www.worldometers.info/world-population/worldpopulation-projections/

[5] Azucar Danny, Davide Marengo, and Michele Settanni. 2018. Predicting the Big 5 personality traits from digital footprints on social media: A meta-analysis. Elsevier Ltd. 1. April 2018. ISSN 01918869. doi:10.1016/j.paid.2017.12.018

[6] Pilař, Ladislav, Tereza Balcarová, Stanislav Rojík, Ivana Tichá and Jana Poláková. 2018. Customer experience with farmers' markets: What hashtags can reveal. International Food and Agribusiness Management Review. 21(6), 755-770. ISSN 15592448. doi:10.22434/IFAMR2017.0039

[7] Pilař, Ladislav, Lucie Kvasničková-Stanislavská, Stanislav Rojík, Roman Kvasnička, Jana Poláková and George Gresham. 2018. Customer experience with organic food: Global view. Emirates Journal of Food and Agriculture. 30,11, 918-926. ISSN 20790538. doi:10.9755/ejfa.2018.v30.i11.1856

[8] Kvasničková-Stanislavská Lucie , Ladislav Pilař, Klára Margarisová and Roman Kvasnička. 2020. Corporate social responsibility and social media: Comparison between developing and developed countries. Sustainability (Switzerland), 12,13, 5255. ISSN 20711050. doi:10.3390/su12135255 
[9] Pilar̆, Ladislav, Lucie Kvasničková-Stanislavská and Roman Kvasnička. 2021. Healthy food on the twitter social network: Vegan, homemade, and organic food. International Journal of Environmental Research and Public Health. 18,7, 3815. ISSN 16604601. doi:10.3390/ijerph18073815

[10] Southern, M. 2018. Instagram Number of Monthly Users Reaches 700 Million. Retrieved May 10, 2021, from https://www.businessinsider.com/instagram-number-of-users-700-million-2017-4

[11] Richter, Felix. 2018. Chart: Instagram's Rise to 1 Billion | Statista. Retrieved May 10, 2021, from https://www.statista.com/chart/9157/instagram-monthly-active-users/

[12] Reisinger, Don. 2018. Instagram's Value Is 100 Times Greater Than When Facebook Bought It | Fortune. Retrieved May 10, 2021, from https://fortune.com/2018/06/26/instagram-facebook-valuation/

[13] Mccormick, Emily. 2018. Instagram Is Estimated to Be Worth More than $\$ 100$ Billion. Retrieved May 10, 2021, from https://www.bloomberg.com/news/articles/2018-06-25/value-of-facebook-s-instagram-estimated-to-top-100-billion

[14] Manas-Viniegra Luis, Patricia Nunez-Gómezand Victoria Tur-Vinest. 2020. Neuromarketing as a strategic tool for predicting how Instagramers have an influence on the personal identity of adolescents and young people in Spain. Heliyon. 6,3, e03578. ISSN 24058440. doi:10.1016/j.heliyon.2020.e03578

[15] Casló Luis, Carlos Flavián, and Sergio Ibáňez-Sánchez. 2020. Influencers on Instagram: Antecedents and consequences of opinion leadership. Journal of Business Research. 117, 510-519. ISSN 01482963. doi:10.1016/j.jbusres.2018.07.005

[16] Hu, Margaret. 2020 Cambridge Analytica's black box. B.m.: SAGE Publications Ltd. 1. July $2020 . \quad$ ISSN 20539517. doi: $10.1177 / 2053951720938091$

[17] Aria, Massimo and Corrado Cuccurull. 2017. bibliometrix: An R-tool for comprehensive science mapping analysis. Journal of Informetrics. 11(4), 959-975. ISSN 18755879. doi:10.1016/j.joi.2017.08.007

[18] Broadus, R. N. 1987. Toward a definition of "bibliometrics." Scientometrics. 12(5-6), 373-379. ISSN 01389130. doi:10.1007/BF02016680

[19] Cuccurullo, Corrado, Massimo Aria and Fabrizia Sarto. 2016. Foundations and trends in performance management. A twenty-five years bibliometric analysis in business and public administration domains. Scientometrics. 108(2), 595-611. ISSN 15882861. doi:10.1007/s11192-016-1948-8

[20] Purnomo, Agung, Ira Audia Agustina, Andre Septianto, Liahmad and Yanu Endar Prasetyo. 2020. Instagram literature: Insights from scientometric application. In: Proceedings of 2020 International Conference on Information Management and Technology, ICIMTech 2020. B.m.: Institute of Electrical and Electronics Engineers Inc., 2020, p. 583-587. ISBN 9781728170718. doi:10.1109/ICIMTech50083.2020.9211115

[21] Boczkowski, Pablo J., Mora Matassi and Eugenia Mitchelstein. 2018. How young users deal with multiple platforms: The role of meaningmaking in social media repertoires. Journal of Computer-Mediated Communication. 23(5), 245-259. ISSN 10836101. doi:10.1093/jcmc/zmy012

[22] Erz, Antonia, Ben Marder and Elena Osadchaya. 2018. Hashtags: Motivational drivers, their use, and differences between influencers and followers. Computers in Human Behavior. 89, 48-60. ISSN 07475632. doi:10.1016/j.chb.2018.07.030

[23] Fraustino, Julia Daisy, Ji Young Lee, Sang Yeal Lee and Hongmin Ahn. 2018. Effects of $360^{\circ}$ video on attitudes toward disaster communication: Mediating and moderating roles of spatial presence and prior disaster media involvement. Public Relations Review. 44(3), 331-341. ISSN 03638111. doi:10.1016/j.pubrev.2018.02.003

[24] Mazhar Rathore, M., Awais Ahmad, Anand Paul, Won Hwa Hong and Hyun Cheol Seo. 2017. Advanced computing model for geosocial media using big data analytics. Multimedia Tools and Applications. 76(23), 24767-24787. ISSN 15737721. doi:10.1007/s11042-0174644-7

[25] Cenni, Daniele, Paolo Nesi, Gianni Pantaleo and Imad Zaza. 2017. Twitter vigilance: A multi-user platform for cross-domain Twitter data analytics, NLP and sentiment analysis. In: IEEE SmartWorld, Ubiquitous Intelligence \& Computing, Advanced \& Trusted Computed, Scalable Computing \& Communications, Cloud \& Big Data Computing, Internet of People and Smart City Innovation (SmartWorld/SCALCOM/UIC/ATC/CBDCom/IOP/SCI) [online]. B.m.: IEEE, 2017. ISBN 978-1-5386-0435-9. doi:10.1109/UICATC.2017.8397589

[26] Sherman, Lauren E., Patricia M. Greenfield, Leanna M. Hernandez and Mirella Dapretto. 2018. Peer Influence Via Instagram: Effects on Brain and Behavior in Adolescence and Young Adulthood. Child Development. 89(1), 37-47. ISSN 14678624. doi:10.1111/cdev.12838

[27] Balan, Carmen. 2017. Does brand posting behaviour influence follower engagement on Instagram? Proceedings of the International Conference on Business Excellence. 11(1), 687-697. ISSN 2558-9652. doi:10.1515/picbe-2017-0073

[28] Casaló, Luis v., Carlos Flavián and Sergio Ibáňez-Sánchez. 2020. Influencers on Instagram: Antecedents and consequences of opinion leadership. Journal of Business Research. 117, 510-519. ISSN 01482963. doi:10.1016/j.jbusres.2018.07.005

[29] Purnomo, Agung, Ira Audia Augustina, Andre Septianto, Liahmad and Yanu Endar Prasetyo. 2020. Instagram literature: Insights from scientometric application. In: Proceedings of 2020 International Conference on Information Management and Technology, ICIMTech. B.m.: Institute of Electrical and Electronics Engineers Inc., 2020, p. 583-587. ISBN 9781728170718. doi:10.1109/ICIMTech50083.2020.9211115

[30] Döring, Nicola, Anne Reif and Sandra Poeschl. 2016. How gender-stereotypical are selfies? A content analysis and comparison with magazine adverts. Computers in Human Behavior. 55, 955-962 ISSN 07475632. doi:10.1016/j.chb.2015.10.001

[31] Ye, Zhang, Noor Hazarina Hashim, Fakhri Baghirov and Jamie Murphy. 2018. Gender Differences in Instagram Hashtag Use. Journal of Hospitality Marketing and Management. 27(4), 386-404. ISSN 19368631. doi:10.1080/19368623.2018.1382415

[32] Jeon, Youngseung, Seung Gon Jeon and Kyungsik Han. 2020. Better targeting of consumers: Modeling multifactorial gender and biological sex from Instagram posts. User Modeling and User-Adapted Interaction. 30(5), 833-866. ISSN 15731391. doi:10.1007/s11257020-09260-w

[33] Li, Yi, Xiuxiu Xu, Bo Song and Hong He. 2020. Impact of short food videos on the tourist destination image-Take Chengdu as an example. Sustainability (Switzerland) [online]. 12(17). ISSN 20711050. doi:10.3390/SU12176739

[34] Feher, Katalin. 2021. Digital identity and the online self: Footprint strategies - An exploratory and comparative research study. Journal of Information Science. 47(2), 192-205 ISSN 17416485. doi:10.1177/0165551519879702

[35] Yang, Jing, Jasmine Fardouly, Yuhui Wang and Wen Shi. 2020. Selfie-viewing and facial dissatisfaction among emerging adults: A moderated mediation model of appearance comparisons and self-objectification. International Journal of Environmental Research and Public Health. 17(2), 672 ISSN 16604601. doi:10.3390/ijerph17020672 
[36] Mccrory, Alanna, Paul Best and Alan Maddock. 2020. The relationship between highly visual social media and young people's mental health: A scoping review. Children and Youth Services Review. 115. ISSN 01907409. doi:10.1016/j.childyouth.2020.105053

[37] Lemay, David John, Paul Bazelais and Tenzin Doleck. 2020. Patterns of social networking use and academic performance: Examining the link between quality and frequency of social networking use and academic performance among college-level students. Education and Information Technologies. 25(3), 2261-2273. ISSN 15737608. doi:10.1007/s10639-019-10065-7

[38] Sheldon, Pavica and Katherine Bryant. 2016. Instagram: Motives for its use and relationship to narcissism and contextual age. Computers in Human Behavior. 58, 89-97. ISSN 07475632. doi:10.1016/j.chb.2015.12.059

[39] Meng, Keira Shuyang and Louis Leung. 2021. Factors influencing TikTok engagement behaviors in China: An examination of gratifications sought, narcissism, and the Big Five personality traits. Telecommunications Policy.45(7), 102172. ISSN 03085961. doi:10.1016/j.telpol.2021.102172

[40] Sheldon, Pavica and Katherine Bryant. 2016. Instagram: Motives for its use and relationship to narcissism and contextual age. Computers in Human Behavior. 2016, 58, 89-97. ISSN 07475632. doi:10.1016/j.chb.2015.12.059

[41] Grieve, Rachel, Cathryne P. Lang and Evita March. 2021. More than a preference for online social interaction: Vulnerable narcissism and phubbing. Personality and Individual Differences. 175, 110715. ISSN 01918869. doi:10.1016/j.paid.2021.110715

[42] Sheldon, Pavica, Philipp A. Rauschnabel and James M. Honeycutt. 2019. Narcissism as a Predictor of Self-Presentation. In: The Dark Side of Social Media. B.m.: Elsevier, p. 23-41. doi:10.1016/b978-0-12-815917-0.00002-2

[43] Okazaki, Shintaro, Florian Schuberth, Takumi Tagashira and Victoria Andrade. 2019. Sneaking the dark side of brand engagement into Instagram: The dual theory of passion. Journal of Business Research. 130, 493-505. ISSN 01482963. doi:10.1016/j.jbusres.2019.11.028

[44] Tiggemann, Marika, Isabella Anderberg and Zoe Brown. 2020. \#Loveyourbody: The effect of body positive Instagram captions on women's body image. Body Image.33, 129-136. ISSN 17401445. doi:10.1016/j.bodyim.2020.02.015

[45] Cohen, Rachel, Toby Newton-John and Amy Slater. 2017. The relationship between Facebook and Instagram appearance-focused activities and body image concerns in young women. Body Image, 23, 183-187. ISSN 17401445. doi:10.1016/j.bodyim.2017.10.002

[46] Brown, Zoe and Marika Tiggemann. 2016. Attractive celebrity and peer images on Instagram: Effect on women's mood and body image. Body Image.19, 37-43. ISSN 17401445. doi:10.1016/j.bodyim.2016.08.007

[47] Jiang, Shaohai and Annabel Ngien. 2020. The Effects of Instagram Use, Social Comparison, and Self-Esteem on Social Anxiety: A Survey Study in Singapore. Social Media and Society. 6(2). ISSN 20563051. doi:10.1177/2056305120912488

[48] Elhai, Jon D., Mojisola Tiamuyu and Justin Weeks. 2018. Depression and social anxiety in relation to problematic smartphone use: The prominent role of rumination. Internet Research. 28(2). ISSN 10662243. doi:10.1108/IntR-01-2017-0019

[49] Baker, Nicole, Ginette Ferszt and Juliana G. Brienes. 2019. A Qualitative Study Exploring Female College Students' Instagram Use and Body Image. Cyberpsychology, Behavior, and Social Networking. 22(4), 277-282 ISSN 21522723. doi:10.1089/cyber.2018.0420

[50] Tiggemann, Marika. 2010. Mental health risks of self-objectification: A review of the empirical evidence for disordered eating, depressed mood, and sexual dysfunction. In: Self-objectification in women: Causes, consequences, and counteractions. B.m.: American Psychological Association, 2010, p. 139-159. doi:10.1037/12304-007

[51] Wang, Ruoxu, Fan Yang and Michel M. Haigh. 2017. Let me take a selfie: Exploring the psychological effects of posting and viewing selfies and groupies on social media. Telematics and Informatics. 2017, 34(4), 274-283. ISSN 07365853. doi:10.1016/j.tele.2016.07.004

[52] Saunders, Jessica F. and Asia A. Eaton. 2018. Snaps, selfies, and shares: How three popular social media platforms contribute to the sociocultural model of disordered eating among young women. Cyberpsychology, Behavior, and Social Networking. 21(6), 343-354. ISSN 21522723. doi:10.1089/cyber.2017.0713

[53] Cohen, Rachel, Toby Newton-John and Amy Slater. 2017. The relationship between Facebook and Instagram appearance-focused activities and body image concerns in young women. Body Image. 23, 183-187. ISSN 17401445. doi:10.1016/j.bodyim.2017.10.002

[54] Fredrickson, Barbara L., Tomi-Ann Roberts, Stephanie M. Noll, Diane M. Quinn and Jean M. Twenge. 1998. That swimsuit becomes you: Sex differences in self-objectification, restrained eating, and math performance. Journal of Personality and Social Psychology. 75(1), 269-284. ISSN 0022-3514. doi:10.1037//0022-3514.75.1.269

[55] Fox, Jesse, Megan A. Vendemia, Marisa A. Smith and Natalie R. Brehm. 2021. Effects of taking selfies on women's self-objectification, mood, self-esteem, and social aggression toward female peers. Body Image. 36, 193-200. ISSN 17401445. doi:10.1016/j.bodyim.2020.11.011

[56] Tiggemann, Marika and Isabella Barbato. 2018: “You look great!": The effect of viewing appearance-related Instagram comments on women's body image. Body Image. 27, 61-66. ISSN 17401445. doi:10.1016/j.bodyim.2018.08.009

[57] Cavus, Nadire; Sani, Abdullahi S.; Haruna, Yusuf; Lawan, Abdulmalik A. 2021. "Efficacy of Social Networking Sites for Sustainable Education in the Era of COVID-19: A Systematic Review" Sustainability 13, no. 2: 808. https://doi.org/10.3390/su13020808

[58] Wahid, R. B., Hasim, M. A. and Hashim, S. (2020) 'Influences of Media Richness on Instagram towards Consumer Purchase Intention: The Mediating Effect of Brand Equity', International Journal of Innovation, Creativity and Change, 10(11), p. 2020.

[59] Highfield, T. and Leaver, T. (2014) 'A methodology for mapping Instagram hashtags', First Monday. doi: 10.5210/fm.v20i1.5563.

[60] Perriam, J., Birkbak, A. and Freeman, A. (2020) 'Digital methods in a post-API environment', International Journal of Social Research Methodology, 23(3), pp. 277-290. doi: 10.1080/13645579.2019.1682840.

[61] Savitri, S. and Irwansyah, I. (2021) 'The Use of Instagram Stories at the Age of COVID-19 Pandemic', Jurnal ASPIKOM, 6(1), pp. 182196. doi: 10.24329/aspikom.v6i1.750.

[62] Masciantonio, A., Bourguignon, D., Bouchat, P., Balty, M. and Rimé, B. (2021) 'Don't put all social network sites in one basket: Facebook, Instagram, Twitter, TikTok, and their relations with well-being during the COVID-19 pandemic', PLOS ONE, 16(3), p. e0248384. doi: 10.1371/journal.pone.0248384

[63] Pilař, Ladislav; Kvasničková Stanislavská, Lucie; Pitrová, Jana; Krejčí, Igor; Tichá, Ivana; Chalupová, Martina. 2019. "Twitter Analysis of Global Communication in the Field of Sustainability" Sustainability 11, no. 24: 6958. https://doi.org/10.3390/su11246958

[64] Pilar̆ Ladislav, Rojík, Stanislav, Balcarová Tereza, Pitrová, Jana. 2016. Gamification in Education: Current state. doi:10.13140/RG.2.1.1348.5682.

[65] Pilař, Ladislav; Stanislavská, Lucie K.; Kvasnička, Roman; Hartman, Richard; Tichá, Ivana. 2021. "Healthy Food on Instagram Social Network: Vegan, Homemade and Clean Eating" Nutrients 13, no. 6: 1991. https://doi.org/10.3390/nu13061991 